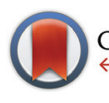

CrossMark $\leftarrow$ click for updates

Cite this: Dalton Trans., 2014, 43 13307

Received 13th March 2014,

Accepted 8th July 2014

DOI: 10.1039/c4dt00761a

www.rsc.org/dalton

\section{Supramolecular activation of a molecular photocatalyst $\uparrow$}

\author{
Michael G. Pfeffer, ${ }^{a}$ Christian Pehlken, ${ }^{a}$ Robert Staehle,,${ }^{a, b}$ Dieter Sorsche, ${ }^{a}$ \\ Carsten Streb ${ }^{a}$ and Sven Rau*a
}

\section{Introduction}

Photocatalytic dyads based on hetero-oligonuclear complexes, i.e. for intramolecular photocatalysis, are an intriguing development at the interface between molecular catalysis, photochemistry and energy science. The ability to combine molecular building blocks carrying specific functions into large functional units is a prerequisite for this area. This general concept has been termed photochemical molecular devices (PMD). ${ }^{1}$ In order to generate photocatalytically active PMDs the following functionalities are required: visible light absorption, generation of reactive, long lived charge separated states, directional electron transfer between the catalytic site and the photocentre and catalytic transformation of the substrate at the catalytic site. Recent examples of intramolecular photocatalysts include water oxidation catalysts, water reduction catalysts and carbon dioxide reducing catalysts. ${ }^{2-11}$ In direct comparison with intermolecular ${ }^{12-16}$ and heterogeneous photocatalysts, ${ }^{17-20}$ intramolecular photocatalysis, however, often suffer from lower catalytic activity. It is therefore of paramount importance to learn more about the factors

\footnotetext{
${ }^{a}$ University of Ulm, Institute of Inorganic Chemistry Materials and Catalysis, AlbertEinstein-Allee 11, 89081 Ulm, Germany.E-mail:sven.rau@uni-ulm.de; Fax: +49731 5023039; Tel: +497315023900

${ }^{b}$ Friedrich-Alexander-University of Erlangen-Nuremberg, Institute of Inorganic Chemistry, Egerlandstraße 1, 91058 Erlangen, Germany

$\dagger$ Electronic supplementary information (ESI) available. CCDC 987314. For ESI and crystallographic data in CIF or other electronic format see DOI: $10.1039 / \mathrm{c} 4 \mathrm{dt} 00761 \mathrm{a}$
}

determining the catalytic activity of intramolecular photocatalysts. Towards this aim two main routes may be envisaged: (i) the synthesis of new catalysts; ${ }^{21,22}$ (ii) the optimization of existing catalytic systems by supplying activating additives. As it is currently not fully clear which design criteria have to be taken into consideration for the de novo synthesis of active catalysts, route (ii) deserves further attention. Route (ii) can be taken by screening properties of the catalytic system like solvent composition, $\mathrm{pH}$ value and ionic additives. ${ }^{5,7,23-27}$ Within this research, it has, for instance, been shown that the addition of $\mathrm{N}\left(\mathrm{C}_{4} \mathrm{H}_{9}\right)_{4} \mathrm{Cl}$ to the photocatalytic system for the light induced formation of hydrogen from water based on $\left[\mathrm{Ru}(\mathrm{tbbpy})_{2}(\mathrm{tpphz})-\right.$ $\left.\mathrm{PdCl}_{2}\right]\left(\mathrm{PF}_{6}\right)_{2}$ (RutpphzPd) (ruthenium(II)-bis(4,4'-di-tert-butyl2,2'-bipyridyl)-( $\mu$-tetrapyrido[3,2-a:2',3'-c:3", $\left.2^{\prime \prime}-h: 2^{\prime \prime \prime}, 3^{\prime \prime \prime}-j\right]$ phenazine)(dichloropalladium)-dihexafluorophosphate) (Fig. 1) leads to a significant drop in catalytic activity. This has been explained by the inhibition of a chloride ligand loss from the catalytic centre, a process crucial for catalytic turnover. ${ }^{7}$ Furthermore, the photocatalytic activity of this system can be increased by addition of appropriate amounts of water ${ }^{21,22,28}$ and completely inhibited by changing the solvent to dichloromethane. ${ }^{7}$ Since the photocatalytic activity of this molecular system is dependent on the interplay between photochemical electron transfer and catalytic steps in combination with the molecular building blocks all occurring within the molecular architecture, a careful analysis of these steps should provide new starting points for the investigation of new activating additives. The starting point is the structural analysis, which shows that RutpphzPd features a planar polyaromatic tetrapyridophenazine bridging ligand. The mononuclear parent ruthenium 

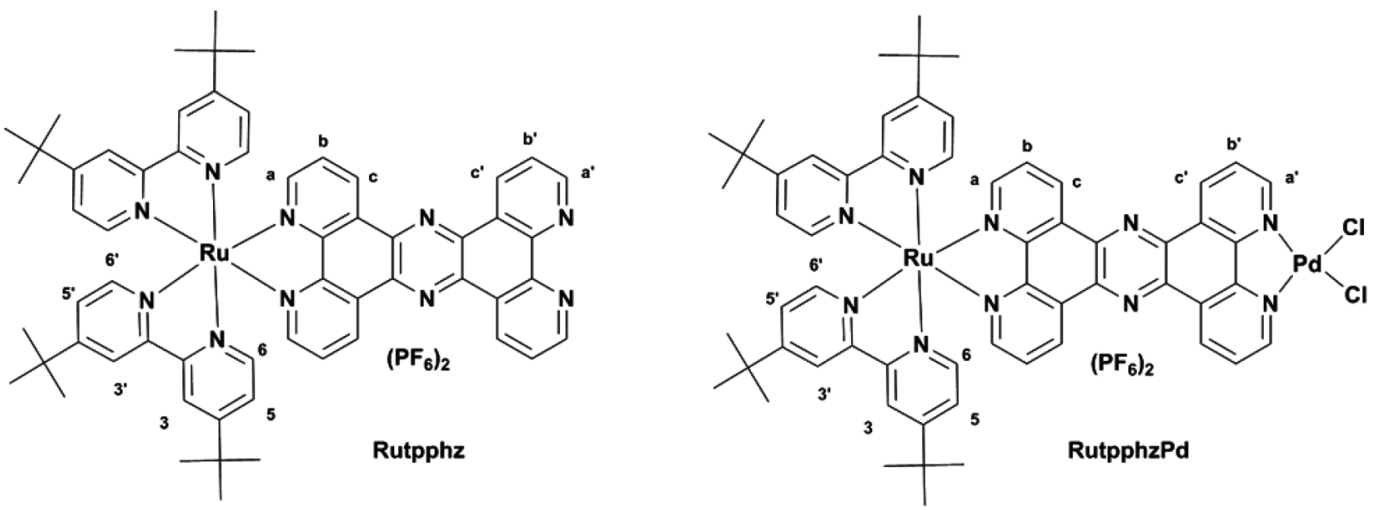

Fig. 1 Structure of the ruthenium complexes and assignments of the ligand protons.

complex $\left[\mathrm{Ru}(\text { tbbpy })_{2}(\right.$ tpphz) $)\left(\mathrm{PF}_{6}\right)_{2}$ Rutpphz (Fig. 1) exhibits significant $\pi-\pi$-interactions in the solid state and a concentration dependent ${ }^{1} \mathrm{H}-\mathrm{NMR}$ spectrum is observed. ${ }^{7}$ The planar ligand structure has previously been utilized for detailed dimerization studies of the related mononuclear ruthenium complex $\left[\mathrm{Ru}(\mathrm{bpy})_{2}(\mathrm{tpphz})\right]\left(\mathrm{PF}_{6}\right)_{2}$ in solution. ${ }^{29-33}$ More recently the DNA intercalation of tpphz-based Ru complexes has been utilized to access reversible luminescent switches. ${ }^{34,35}$

Here, we present a concise route, which allows optimization of the photocatalytic activity of RutpphzPd by controlling the supramolecular aggregation in solution. The concept uses polycyclic aromatic hydrocarbons to form $\pi-\pi$-interactions with the planar tpphz ligand, resulting in a dis-assembly of the $\pi$-stacked catalyst aggregates in solution.

\section{Experimental}

\section{Starting materials}

Anthracene (Anth) and pyrene (Pyr) were purchased from commercial sources and used without further purification. [Ru(tbbpy $)_{2}($ tpphz) $]\left(\mathrm{PF}_{6}\right)_{2}$ (Rutpphz) and [Ru(tbbpy $\left.)_{2}(\mathrm{tpphz}) \mathrm{PdCl}_{2}\right]-$ $\left(\mathrm{PF}_{6}\right)_{2}$ (RutpphzPd) were prepared according to literature methods. ${ }^{36}$ All solvents used for the photocatalytic experiments were degassed with argon.

\section{Crystal structure determination}

Crystals of $\left[(\text { tbbpy })_{2} \mathrm{Ru}(\text { tpphz) }) \mathrm{Pd}(\mathrm{Cl})_{2}\right]_{2}\left[\mathrm{Mo}_{8} \mathrm{O}_{26}\right] c a$. 18 DMF. $2 \mathrm{H}_{2} \mathrm{O}$ suitable for X-ray diffraction crystallography were obtained by diffusion of a DMF solution of $\left[\mathrm{Ru}(\mathrm{tbbpy})_{2}(\mathrm{tpphz})-\right.$ $\left.\mathrm{PdCl}_{2}\right]\left(\mathrm{PF}_{6}\right)_{2}$ into a DMF solution of $(\mathrm{TBA})_{2}\left[\mathrm{Mo}_{6} \mathrm{O}_{19}\right](\mathrm{TBA}=$ tetrabutylammonium) at $8{ }^{\circ} \mathrm{C}$.

The crystal was mounted onto a MicroLoop ${ }^{\mathrm{TM}}$ using Fomblin oil. X-ray diffraction intensity data were measured at $180 \mathrm{~K}$ on an Agilent Technologies SuperNova single-crystal X-ray diffractometer using MoKo radiation. The structure was solved by direct methods (SHELXS) and refined by full-matrix least squares techniques against $F_{\mathrm{o}}{ }^{2}$ (SHELXL-2013). ${ }^{37}$ During the refinement, significant disorder of the solvent DMF molecules in the crystal lattice was observed. Three DMF molecules and one oxygen atom corresponding to water were refined anisotropically, and three DMF molecules were refined isotropically with fixed coordinates. For the remaining solvent accessible voids within the lattice, the Platon Squeeze procedure was applied to remove diffuse electron density. Based on the accessible void space, the amount of DMF within the voids was estimated to be eight DMF molecules. ${ }^{38,39}$ It is noteworthy that according to the obtained data, the ion lattice of the ruthenium-palladium complex and the molybdate cluster only accounts for approximately $50 \%$ of the crystal volume.

The hydrogen atoms were included at calculated positions with fixed thermal parameters. All non-hydrogen atoms of the molybdate cluster and the RuPd complex were refined anisotropically.

Crystal data for [(tbbpy $\left.)_{2} \mathrm{Ru}(\mathrm{tpphz}) \mathrm{Pd}(\mathrm{Cl})_{2}\right]_{2}\left[\mathrm{Mo}_{8} \mathrm{O}_{26}\right] c a .18$ DMF. $2 \mathrm{H}_{2} \mathrm{O}: \mathrm{C}_{168} \mathrm{H}_{232} \mathrm{Cl}_{4} \mathrm{Mo}_{8} \mathrm{~N}_{38} \mathrm{O}_{44} \mathrm{Pd}_{2} \mathrm{Ru}_{2}, \quad M_{\mathrm{r}}=4812.16 \mathrm{~g}$ $\mathrm{mol}^{-1}$, orange block, crystal size $0.1336 \times 0.067 \times 0.0623 \mathrm{~mm}^{3}$, triclinic, space group $P \overline{1}, a=14.6799(3), b=19.1828(4), c=$ 22.7309(5) $\AA, \alpha=103.457(2)^{\circ}, \beta=106.027(2), \gamma=104.881(2), V=$ $5619.3(2) \AA^{3}, T=180 \mathrm{~K}, Z=1, \rho_{\text {calcd }}=1.422 \mathrm{~g} \mathrm{~cm}^{-3}, \mu(\mathrm{Mo}-\mathrm{K} \alpha)=$ $0.836 \mathrm{~mm}^{-1}, F(000)=2442$, altogether 72507 independent reflexes up to $h(-18 / 18), k(-23 / 23), l(-28 / 28)$ measured in the range of $3.4^{\circ} \leq \Theta \leq 26.372^{\circ}$, completeness $\Theta_{\max }=99.7 \%$, 22937 unique reflections, $R_{\text {int }}=0.046,22937$ reflections with $F_{\mathrm{o}}>4 \sigma\left(F_{\mathrm{o}}\right), 1007$ parameters, 18 restraints, $R_{1 \mathrm{obs}}=0.0447$, $\mathrm{w} R_{\text {2obs }}=0.1337, R_{1 \text { all }}=0.0744, \mathrm{w}_{\text {2all }}=0.1442, \mathrm{GOOF}=0.705$, largest difference peak and hole: $0.990 /-0.546$ e $\AA^{-3}$. CCDC 987314 contains the supplementary crystallographic data for this paper.

\section{Instrumentation}

${ }^{1} \mathrm{H}(400.13 \mathrm{MHz})$ spectra were measured using a Bruker DRX 400 spectrometer. The NMR spectra were recorded in aceto-

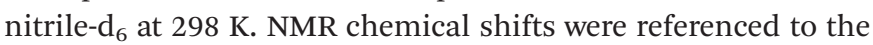
solvent peak for acetonitrile $(\delta=1.94 \mathrm{ppm})$.

MS analysis was performed on a Shimadzu LC-MS 2020 equipped with an electrospray ionisation source and a SPD-20A UV/Vis detector.

The hydrogen evolved was measured by headspace gas chromatography (GC) on a Bruker Scion GC/MS, with a thermal conductivity detector (column: Mol. Sieve 5A $75 \mathrm{~m} \times$ 
$0.53 \mathrm{~mm}$ I.D., oven temp. $70^{\circ} \mathrm{C}$, flow rate $22.5 \mathrm{ml} \mathrm{min}^{-1}$, detector temp. $200{ }^{\circ} \mathrm{C}$ ) with argon as a carrier gas. The GC was calibrated by mixing different volumes of pure hydrogen together with argon into a Schlenk vessel. The obtained signal was plotted against the calibration curve and multiplied accordingly to receive the total produced hydrogen content in the headspace.

The UV/vis-spectra were recorded with a JASCO Spectrometer V-670. Quartz cells with a $10 \mathrm{~mm}$ path length were used.

The emission spectra were recorded using a JASCO Spectrofluorometer FP-8500. Quartz cells with a $10 \mathrm{~mm}$ path length were used. All experiments were repeated 3 times.

If not mentioned otherwise all experiments were performed under aerobic conditions.

\section{Experimental conditions for photocatalytic hydrogen generation}

Photohydrogen production experiments were carried out using a custom-made LED-based irradiation setup, which allowed irradiation at constant temperature (see ESI Fig. S1†). The acetonitrile used was freshly distilled under argon. The samples for the LED light irradiation experiments were prepared in GC vials (diameter $=45 \times 14.75 \mathrm{~mm}$ ) with a known headspace of $3 \mathrm{ml}$ and a headspace-solution ratio of $3 / 2$. Furthermore the GC vials were charged in the dark and under an argon stream. After addition of triethylamine $(V=0.6 \mathrm{ml})$ and $10 \mathrm{vol} \%$ of degassed water $(V=0.20 \mathrm{ml})$ the final catalyst concentration in acetonitrile was $70 \mu \mathrm{M}$. Subsequently, the GC vials were irradiated with blue LED light $(470 \mathrm{~nm}, P=$ 30-40 $\mathrm{mW}$ ). In the case of the addition of anthracene or pyrene, $0.7 \mu \mathrm{mol}$ (5-fold), $11.2 \mu \mathrm{mol}$ (80-fold) or $16.8 \mu \mathrm{mol}$ (120-fold excess to the photocatalyst RutpphzPd) of the aromatic compound were added to the catalytic mixture as a solid. All samples were sonicated for $5 \mathrm{~min}$ to fully dissolve the polyaromatics. After irradiation, $200 \mu \mathrm{l}$ samples were taken from the headspace and instantly analyzed by GC-MS. Irradiation experiments and hydrogen measurements were repeated several times.

\section{${ }^{1} \mathrm{H}$-NMR dimerization and association experiments}

Typically, a concentrated stock solution of the complexes (ca. $10 \mathrm{mM}$ ) and the aromatic compound (ca. $20 \mathrm{mM}$ ) was prepared and the samples were allowed to equilibrate for several minutes. The dimerization constants and the association constant were calculated on the basis of the change of the chemical shift of selected protons following literature methods. $^{42,43,45}$

\section{Results and discussion}

\section{Supramolecular interactions of the Ru-complexes}

Supramolecular $\pi-\pi$-interactions between the aromatic tpphz ligands of Rutpphz in the solid state are well known. ${ }^{7}$ For this reason, we also investigated the solid-state structure of $[\mathrm{Ru}-$ (tbbpy) $)_{2}\left(\right.$ tpphz) $\left.\mathrm{PdCl}_{2}\right]\left(\mathrm{PF}_{6}\right)_{2}$ (RutpphzPd) by single crystal X-ray

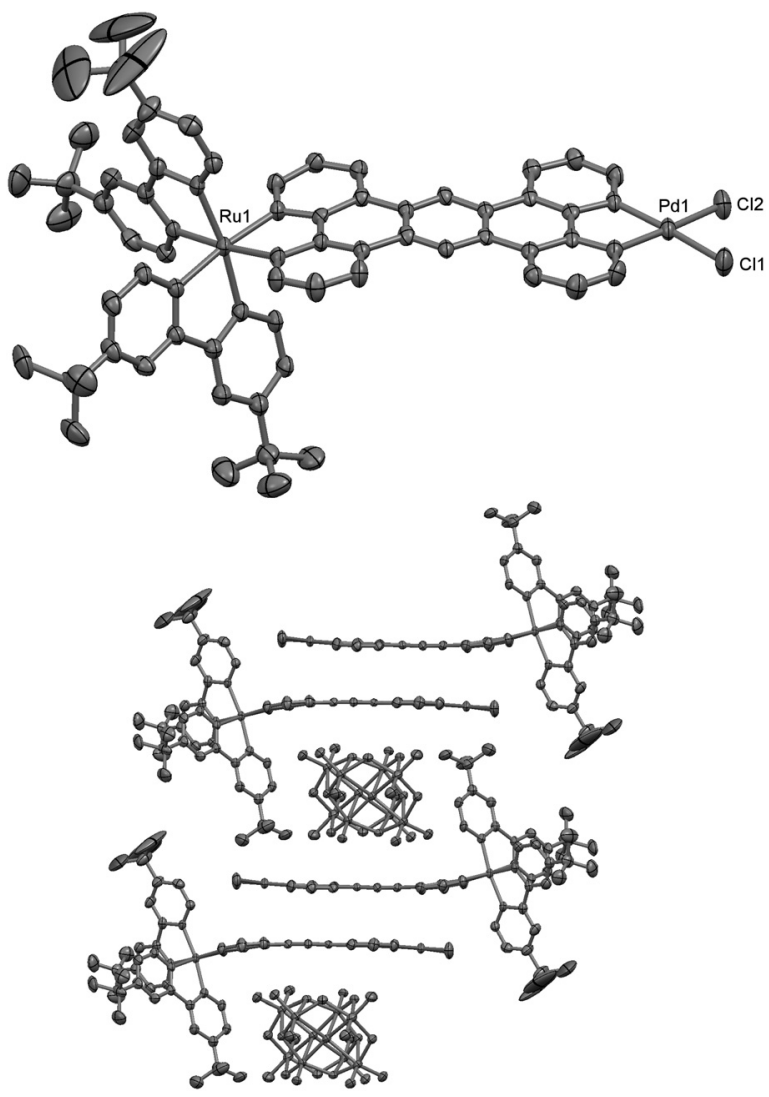

Fig. 2 Top: X-ray crystal structure of the complex cation [Ru$\left(\right.$ tbbpy) ${ }_{2}\left(\text { tpphz) } \mathrm{PdCl}_{2}\right]^{2+}$ (top; ellipsoids at $50 \%$ probability; counter ions, solvent molecules and hydrogen atoms were omitted for clarity) in the solid state. Bottom: Stacking motive of four Ru-complexes and two molybdate clusters in the solid state.

diffractometry. Crystallization was facilitated by addition of a large polyanionic metal oxide cluster. The anion, $\left[\mathrm{Mo}_{8} \mathrm{O}_{24}\right]^{4-}$ was formed in situ by a known re-arrangement reaction starting from $(\mathrm{TBA})_{2}\left[\mathrm{Mo}_{6} \mathrm{O}_{19}\right],{ }^{40}$ giving the complex salt $[\mathrm{Ru}-$ (tbbpy) ${ }_{2}$ (tpphz)PdCl $]_{2}\left[\mathrm{Mo}_{8} \mathrm{O}_{24}\right]$ ca. $18 \mathrm{DMF} \cdot 2 \mathrm{H}_{2} \mathrm{O}$ (Fig. 2). As expected, an octahedral coordination is observed for the ruthenium(II) centre; the palladium(II) centre shows squareplanar coordination mode. All distances and angles are in the expected range. ${ }^{7,41}$ However, it is obvious that the tpphz ligand deviates significantly from planarity and is also not coplanar with the equatorial plane of the ruthenium(II) coordination polyhedron, see Fig. 2.

The Ru-complex forms a cavity in which the anionic metal cluster is embedded. The distance between the mean planes of the tpphz ligands of two RutpphzPd complexes (3.309 $\AA$ ) is marginally smaller than for the mononuclear complex Rutpphz (3.397 $\AA$ ), which shows that $\pi-\pi$-interactions are a crucial aspect for understanding this supramolecular photocatalyst.

\section{Identification of Rutpphz and RutpphzPd by ${ }^{1} \mathrm{H}-\mathrm{NMR}$ spectroscopy}

As expected, ${ }^{1} \mathrm{H}-\mathrm{NMR}$ studies revealed a concentration dependence of the chemical shifts of Rutpphz and RutpphzPd, 


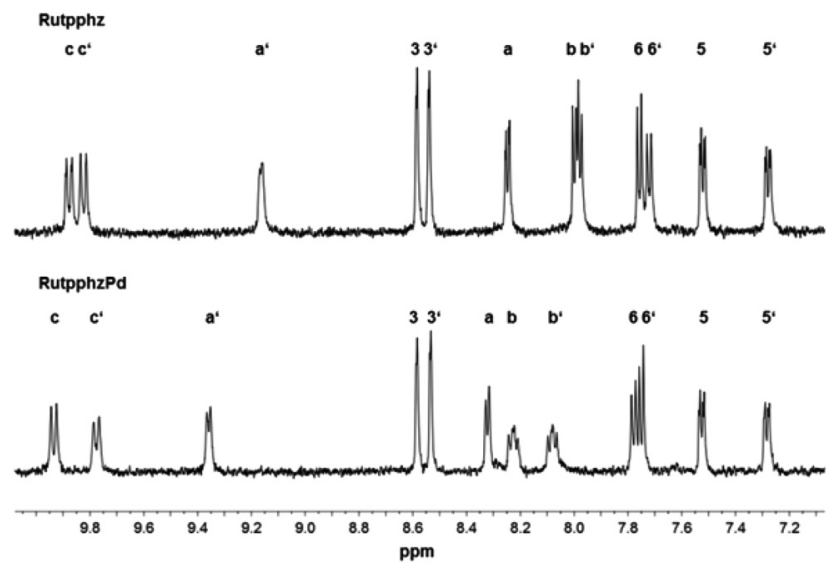

Fig. $3{ }^{1} \mathrm{H}-\mathrm{NMR}$ spectra of Rutpphz and RutpphzPd at a concentration of $1 \mathrm{mM}$ in acetonitrile- $\mathrm{d}_{3}$.

which is due to $\pi$-stacking interactions between the planar tpphz ligands (see ESI Fig. S10 and S12 †). In order to take this concentration dependence into account and due to the fact that both complexes show the identical ${ }^{1} \mathrm{H}$-NMR signal types (Fig. 3), the identification value $I$ was introduced, to facilitate the identification of both species, Rutpphz and RutpphzPd. For this purpose several samples of each complex with defined concentration were prepared and allowed to equilibrate. From the ${ }^{1} \mathrm{H}$-NMR spectra, the identification values $I$ were calculated, based on the chemical shifts of protons $\mathrm{H}^{\mathrm{c}}, \mathrm{H}^{\mathrm{c}^{\prime}}, \mathrm{H}^{\mathrm{a}^{\prime}}$ and $\mathrm{H}^{6}$ (Table S3 $\dagger$ ), where $\mathrm{H}^{\mathrm{c}}, \mathrm{H}^{\mathrm{c}^{\prime}}$ and $\mathrm{H}^{\mathrm{a}^{\prime}}$ belong to the tpphz ligand. $\mathrm{H}^{6}$ belongs to the coordinated bipyridine, which is only marginally affected by the $\pi-\pi$-interaction. ${ }^{29-33}$ Therefore a simple equation was established empirically to convert the particular chemical shift values of protons $\mathrm{H}^{\mathrm{c}}, \mathrm{H}^{\mathrm{c}^{\prime}}, \mathrm{H}^{\mathrm{a}^{\prime}}$ and $\mathrm{H}^{6}$ into a specific identification value $I$ for each complex (eqn (1)).

$$
I=\left(\delta \mathrm{H}^{\mathrm{c}}-\delta \mathrm{H}^{6}\right) \cdot\left(\delta \mathrm{H}^{\mathrm{c}^{\prime}}-\delta \mathrm{H}^{\mathrm{a}^{\prime}}\right)
$$

The difference between the chemical shift values of $\mathrm{H}^{\mathrm{c}}$ and $\mathrm{H}^{6},\left(\delta \mathrm{H}^{\mathrm{c}}-\delta \mathrm{H}^{6}\right)$, is decreasing, whereas the difference of the chemical shift values between $\mathrm{H}^{\mathrm{c}^{\prime}}$ and $\mathrm{H}^{\mathrm{a}^{\prime}},\left(\delta \mathrm{H}^{\mathrm{c}^{\prime}}-\delta \mathrm{H}^{\mathrm{a}^{\prime}}\right)$, is increasing in the same order with a rising complex concentration. The product of both terms delivers a constant value, which is specific for each compound. Within a concentration range of $0.25 \mathrm{mM}$ to $10 \mathrm{mM}$ stable values for $I$ (Rutpphz) $=$ $1.42 \pm 0.04$ and $I$ (RutpphzPd) $=0.89 \pm 0.04$ were obtained. These specific identification values allow for unambiguous identification of Rutpphz and RutpphzPd independent from the concentration of the complex. This procedure was applied throughout the presented investigations for ensuring the purity of the two complexes under scrutiny.

\section{Determination of the dimerization constants for Rutpphz and RutpphzPd}

The $\pi-\pi$ dimerization constant $K_{\pi \text {-D }}$ was determined in acetonitrile according to the method used by Dixon and Lezna. ${ }^{42,43}$ Therefore the magnitude of the shift of the ${ }^{1} \mathrm{H}$-NMR signals of the tpphz protons $\mathrm{H}^{\mathrm{a}^{\prime}}$ and $\mathrm{H}^{\mathrm{c}^{\prime}}$ due to dimerization was
Table 1 Calculated $K_{\pi-\mathrm{D}}\left(\right.$ Rutpphz) values for the tpphz protons $\mathrm{H}^{\mathrm{a}^{\prime}}$ and $\mathrm{H}^{\mathrm{C}^{\prime}}$ and the average value

\begin{tabular}{lll}
\hline$K_{\pi-\mathrm{D}} \mathrm{H}^{\mathrm{c}^{\prime}}$ & $K_{\pi-\mathrm{D}}(\mathrm{av})$ & $K_{\pi-\mathrm{D}} \mathrm{H}^{\mathrm{a}^{\prime}}$ \\
\hline $113 \pm 10 \mathrm{M}^{-1}$ & $122 \pm 19 \mathrm{M}^{-1}$ & $131 \pm 10 \mathrm{M}^{-1}$
\end{tabular}

Table $2{ }^{1} \mathrm{H}$-NMR concentration dependence of Rutpphz and RutpphzPd in acetonitrile- $d_{3}$ with regard to the chemical shifts of protons $\mathrm{H}^{\mathrm{c}}, \mathrm{H}^{\mathrm{c}^{\prime}}$ and $\mathrm{H}^{\mathrm{a}^{\prime}}$

\begin{tabular}{|c|c|c|c|c|c|c|}
\hline \multirow[b]{2}{*}{$\begin{array}{l}c \\
{[\mathrm{mM}]}\end{array}$} & \multicolumn{3}{|c|}{ Rutpphz } & \multicolumn{3}{|c|}{ RutpphzPd } \\
\hline & $\begin{array}{l}\delta \mathrm{H}^{\mathrm{c}} \\
{[\mathrm{ppm}]}\end{array}$ & $\begin{array}{l}\delta \mathrm{H}^{\mathrm{c}^{\prime}} \\
{[\mathrm{ppm}]}\end{array}$ & $\begin{array}{l}\delta \mathrm{H}^{\mathrm{a}^{\prime}} \\
{[\mathrm{ppm}]}\end{array}$ & $\begin{array}{l}\delta \mathrm{H}^{\mathrm{c}} \\
{[\mathrm{ppm}]}\end{array}$ & $\begin{array}{l}\delta \mathrm{H}^{\mathrm{c}^{\prime}} \\
{[\mathrm{ppm}]}\end{array}$ & $\begin{array}{l}\delta \mathrm{H}^{\mathrm{a}^{\prime}} \\
{[\mathrm{ppm}]}\end{array}$ \\
\hline 10 & 9.54 & 9.30 & 8.36 & 9.89 & 9.49 & 9.05 \\
\hline 5.0 & 9.65 & 9.47 & 8.62 & 9.92 & 9.57 & 9.14 \\
\hline 1.0 & 9.82 & 9.75 & 9.07 & 9.91 & 9.69 & 9.27 \\
\hline 0.50 & 9.89 & 9.86 & 9.23 & 9.91 & 9.79 & 9.38 \\
\hline 0.25 & 9.92 & 9.90 & 9.29 & 9.91 & 9.91 & 9.49 \\
\hline
\end{tabular}

analyzed. $K_{\pi-\mathrm{D}}$ was calculated from the extrapolation of the $\delta$ values of $\mathrm{H}^{\mathrm{a}^{\prime}}$ and $\mathrm{H}^{\mathrm{c}^{\prime}}$ of free monomers $\delta_{0}$ and fully stacked species $\delta_{\mathrm{S}}$ as previously reported (see ESI Fig. S11†). ${ }^{42}$ Table 1 shows the calculated values for $K_{\pi \text {-D }}($ Rutpphz).

Kol and coworkers determined this constant for $\left[\mathrm{Ru}\left(\mathrm{bpy}_{2}\right)\right.$ $(\mathrm{tpphz})]\left(\mathrm{PF}_{6}\right)_{2}$ in acetonitrile and calculated $K_{\pi-\mathrm{D}}(\mathrm{av})=185 \pm 75$ $\mathrm{M}^{-1} .{ }^{29}$ These values are slightly different which may be explained with the slight chemical differences between both tpphz complexes. It was not possible to determine this constant for RutpphzPd, as the precision of the extrapolation for $\delta_{0}$ in that concentration range was too low, due to the detection limit of the ${ }^{1} \mathrm{H}-\mathrm{NMR}$ analysis. Nevertheless, a comparison of the change of the ${ }^{1} \mathrm{H}$-NMR signals of $\mathrm{H}^{\mathrm{c}}, \mathrm{H}^{\mathrm{a}^{\prime}}$ and $\mathrm{H}^{\mathrm{c}^{\prime}}$ of Rutpphz and RutpphzPd indicates two trends (Table 2). On the one hand, the signal of $\mathrm{H}^{\mathrm{c}}$ of RutpphzPd is not influenced by dimerization in contrast to $\mathrm{H}^{\mathrm{c}}$ of Rutpphz. This is plausible as the degree of overlap of two RutpphzPd complexes is altered, due to the steric influence of the $\mathrm{PdCl}_{2}$ moiety as seen in Fig. 2. On the other hand, the extent of the peak shift of the protons $\mathrm{H}^{\mathrm{a}^{\prime}}$ and $\mathrm{H}^{\mathrm{c}^{\prime}}$ is much larger for Rutpphz than for RutpphzPd indicating a larger $\pi-\pi$ dimerization constant for Rutpphz.

\section{Interactions between anthracene and pyrene with RutpphzPd}

Due to the $\pi-\pi$-interaction between the planar tpphz ligands of Rutpphz and RutpphzPd a possible interaction of such complexes with other planar aromatic molecules seemed interesting. Anthracene (anth) and pyrene (Pyr) were chosen for this study as model compounds. The interaction between the complexes and the two aromatics was monitored via ESI-mass spectrometry, ${ }^{1} \mathrm{H}-\mathrm{NMR}$ and UV/vis spectroscopy. In addition, association constants were determined to analyze the extent of the interaction.

The mass spectrometry gave first hints for the formation of RutpphzPd-Anth/Pyr adducts. The analysis of the spectral data 
a)

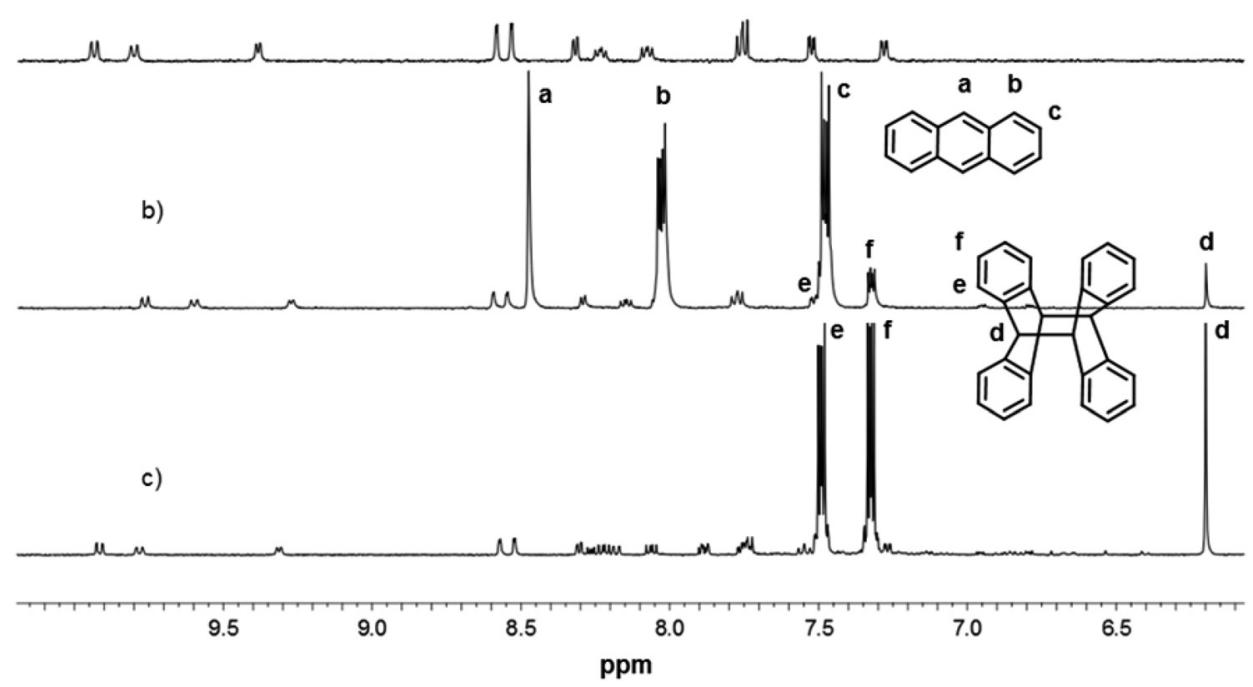

Fig. 4 Changes in the ${ }^{1} \mathrm{H}-\mathrm{NMR}$ spectrum of RutpphzPd with anthracene after visible light irradiation: (a) ${ }^{1} \mathrm{H}-\mathrm{NMR}$ spectrum of RutpphzPd (c = $1 \mathrm{mM}$ ) in acetonitrile- $\mathrm{d}_{3}$; (b) ${ }^{1} \mathrm{H}$-NMR spectrum after the addition of anthracene (c=10 mM) and short exposure to ambient light. (c) ${ }^{1} \mathrm{H}-\mathrm{NMR}$ spectrum after $60 \mathrm{~min}$ of irradiation with LED light $(470 \mathrm{~nm}, 30-40 \mathrm{~mW})$.

of an acetonitrile solution of RutpphzPd with anthracene showed a signal at $m / z=600(z=2)$ corresponding to the divalent cationic adduct between Rutpphz and anthracene. Identical investigations of RutpphzPd and pyrene resulted in the observation of the corresponding Rutpphz-Pyr adduct at $\mathrm{m} / \mathrm{z}=$ $758(z=2)$. The loss of the palladium dichloride moiety readily occurs under ESI-MS conditions. ${ }^{22}$

In the case of anthracene as an interacting agent no association constant could be determined, since a fast photocatalytically induced dimerization of anthracene was competing with the intended supramolecular interaction and thus, the concentration dependent ${ }^{1} \mathrm{H}-\mathrm{NMR}$ investigations were difficult to accomplish. A similar photocatalytic effect was observed by Castellano et al. with $\left[\mathrm{Ru}(\mathrm{dmb})_{3}\right]^{2+}\left(\mathrm{dmb}=4,4^{\prime}\right.$-dimethyl-2,2'bipyridine) as a light absorber, which sensitizes the dimerization of anthracene by visible light. ${ }^{44}$

This has been explained by a triplet-triplet energy transfer from the ruthenium chromophore to anthracene and a subsequent dimerization. Similar to these literature results, our ${ }^{1} \mathrm{H}-\mathrm{NMR}$ spectroscopic investigations on a sample containing RutpphzPd and anthracene in acetonitrile showed, already with ambient light irradiation, a formation of the anthracene dimer (Fig. 4). The effect becomes more pronounced after 60 minutes of LED irradiation $(470 \mathrm{~nm})$ leading to a complete dimer formation as is evident from the ${ }^{1} \mathrm{H}-\mathrm{NMR}$ data in Fig. 4. Similar results were observed for Rutpphz (see ESI Fig. S5 $\dagger$ ).

As illustrated in Fig. 5, the dimerization of anthracene could also be observed via UV/vis spectroscopy in terms of a decreasing concentration of the anthracene monomer. After 120 minutes of LED irradiation $(470 \mathrm{~nm})$, the absorption intensity of the monomer is significantly reduced; however, the decrease is less pronounced compared to the ${ }^{1} \mathrm{H}-\mathrm{NMR}$

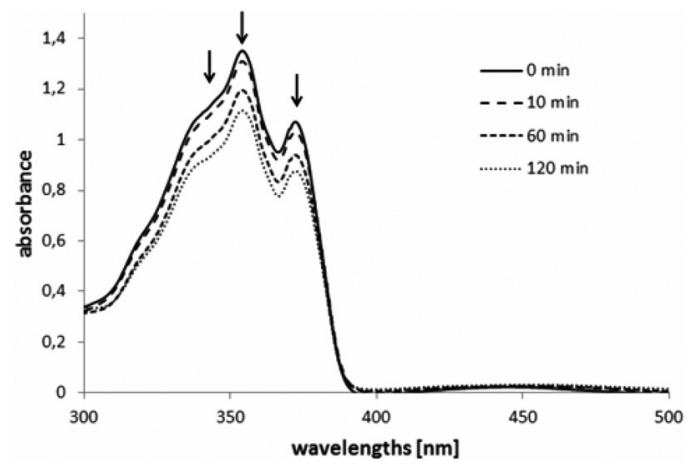

Fig. 5 Changes in the absorption spectrum of anthracene with RutpphzPd in acetonitrile (c(anthracene) $=0.28 \mathrm{mM}, c$ (RutpphzPd) $=$ $3.5 \mu \mathrm{M}$, vol\% $\left.\left(\mathrm{H}_{2} \mathrm{O}\right)=0.5 \%\right)$ with continuous LED light irradiation $(470 \mathrm{~nm})$.

investigations, since much lower concentrations of anthracene were used due to technical requirements.

In contrast to anthracene, the interaction between RutpphzPd and pyrene can be analyzed via ${ }^{1} \mathrm{H}-\mathrm{NMR}$ spectroscopy because pyrene shows no dimerization or other changes due to irradiation. Here, as expected, one can observe a pronounced influence of pyrene on the ${ }^{1} \mathrm{H}$-NMR spectroscopic data of the ruthenium complex (Fig. 6). To evaluate the type of interaction the method of continuous variation (Job's method) for ${ }^{1} \mathrm{H}-\mathrm{NMR}$ data was used, ${ }^{45}$ which suggested a $1 / 1$ stoichiometry for the RutpphzPd-Pyr adduct (see ESI Fig. S7†).

After the determination of the stoichiometry the association constant was calculated using a nonlinear global curve fitting treatment ${ }^{45,46}$ of concentration dependent ${ }^{1} \mathrm{H}$-NMR spectro- 


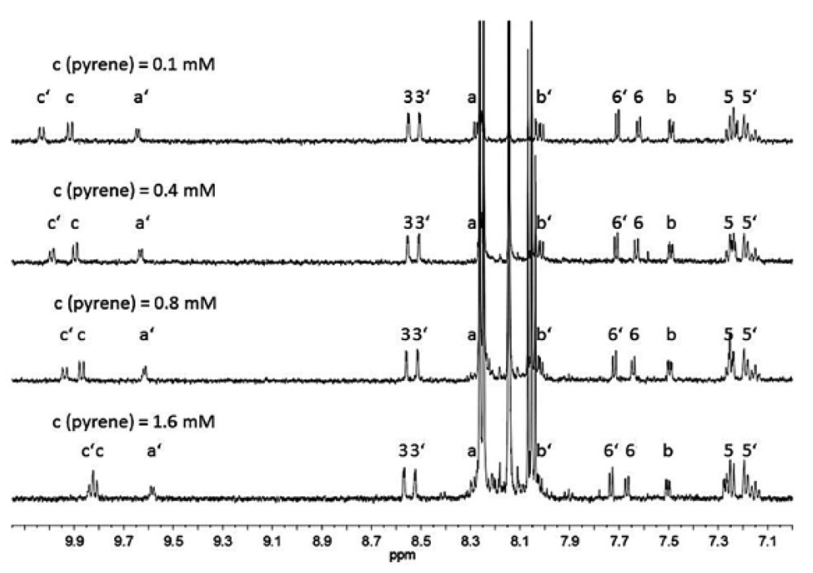

Fig. 6 Excerpt of ${ }^{1} \mathrm{H}-\mathrm{NMR}$ dependence of the chemical shifts of RutpphzPd ( $c=0.1 \mathrm{mM}$ ) on the concentration of pyrene in acetonitrile- $d_{3}$.

scopic data of RutpphzPd and pyrene, which resulted in an association constant of $K_{\mathrm{a}}=155 \pm 44 \mathrm{M}^{-1}$ (see ESI Fig. S8†).

\section{Photocatalysis}

As the chemical environment of RutpphzPd is significantly altered by the addition of pyrene (Pyr) and a $1 / 1$ adduct is formed, investigations into the effect of pyrene and the related anthracene on photocatalytic hydrogen evolution were performed. The formation of the $1 / 1$ adduct is to compete with the dimerization of the complex (eqn (2)).

$$
\begin{gathered}
(\text { RutpphzPd })_{2} \rightleftarrows 2 \text { RutpphzPd } \\
\text { RutpphzPd }+ \text { Pyr } \rightleftarrows(\text { RutpphzPd } \cdots \text { Pyr })
\end{gathered}
$$

In fact the dimerization should only play a minimal role during photocatalysis, as the dimerization constant of Rutpphz is relatively small and the concentration dependent shift of the proton signals of RutpphzPd is less pronounced for Rutpphz. Therefore the amount of dimerized complexes within the concentration range of the catalytic mixtures should only be marginal.

During the experiments, 5-fold, 80-fold and 120-fold* molar excess of pyrene with respect to the complex concentration was added to a catalytic mixture of the following composition: $c($ RutpphzPd $)=70 \mu \mathrm{M}, V(\mathrm{TEA})=0.6 \mathrm{ml}(2.2 \mathrm{M}), V(\mathrm{ACN})=$ $1.2 \mathrm{~mL}, V\left(\mathrm{H}_{2} \mathrm{O}\right)=0.2 \mathrm{~mL}$. Due to the obtained RutpphzPd-Pyr association constant maximal equilibrium concentrations of $c$ (RutpphzPd-Pyr) can be estimated for the pyrene containing system (Table 3 ). Thus about one in twenty catalyst molecules interact with pyrene for a 5 -fold excess and about every second molecule for an 80-fold and 120-fold excess.

In addition a catalytic mixture with an 80-fold excess of anthracene was investigated. As this combination performs in the absence of the electron donor TEA photocatalytic dimerization of anthracene, we were curious whether this photocatalytic process inhibits the photocatalytic hydrogen production. To investigate the effect of the supramolecular
Table 3 Potential equilibrium concentration of the RutpphzPd-Pyr adduct in the catalytic mixture; $K_{\mathrm{a}}=155 \mathrm{M}^{-1}$, [RutpphzPd] $]_{0}=70.0 \mu \mathrm{mol}$

\begin{tabular}{lrll}
\hline Excess pyrene & {$[\mathrm{Pyr}]_{0}$} & {$[$ RutpphzPd-Pyr $]$} & $\begin{array}{l}\text { Degree of association } \\
\text { [RutpphzPd-Pyr }] / \\
{[\text { RutpphzPd }]_{0}}\end{array}$ \\
\hline 5-fold & $350 \mu \mathrm{mol}$ & $3.6 \mu \mathrm{mol}$ & $5.1 \%$ \\
80-fold & $5600 \mu \mathrm{mol}$ & $32.4 \mu \mathrm{mol}$ & $46.3 \%$ \\
120-fold & $8400 \mu \mathrm{mol}$ & $39.5 \mu \mathrm{mol}$ & $56.4 \%$
\end{tabular}

${ }^{*}$ Represents maximal concentration obtainable due to solubility.

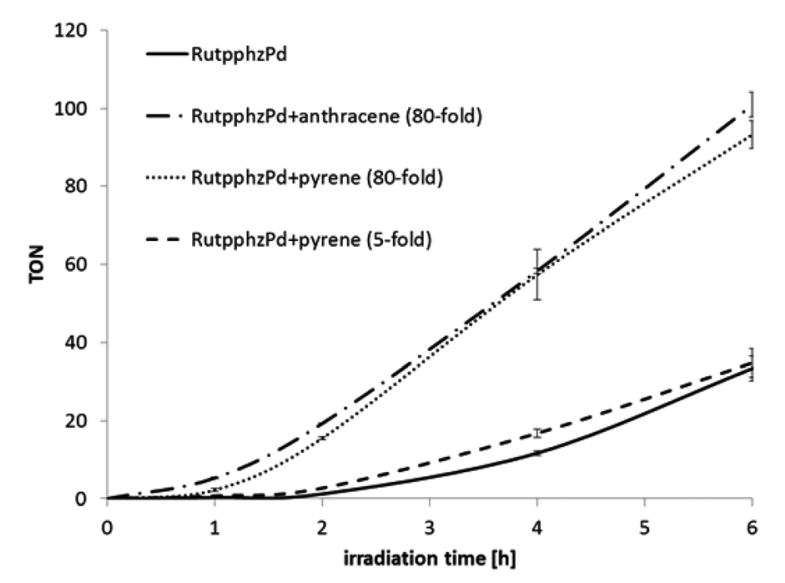

Fig. 7 Induction period of photocatalytic hydrogen production of RutpphzPd ( $c=70 \mu \mathrm{M})$, RutpphzPd + anthracene ( 80 -fold excess) and RutpphzPd + pyrene ( 80 -fold and 5 -fold excess) depending on the irradiation time; TON $=n\left(\mathrm{H}_{2}\right) / n($ RutpphzPd). Error bars indicate the standard error of each value.

interactions on the kinetics of the photocatalytic hydrogen production, the samples containing the photocatalyst in combination with either anthracene or pyrene were compared to samples containing only the photocatalyst. All probes were prepared and kept under an oxygen free atmosphere and irradiated with LED light $(470 \mathrm{~nm})$ of the same intensity. After a specific irradiation time the amount of produced hydrogen was determined via headspace GC.

It is apparent that the addition of an 80-fold excess of anthracene or pyrene leads to significant acceleration of the photocatalytic hydrogen production (Fig. 7).

Especially the induction period, which lasts about 2 hours for RutpphzPd is shortened to less than 1 hour in the presence of an 80-fold excess of anthracene or pyrene. The addition of a 5 -fold excess of pyrene leads to no significant changes in the catalytic behaviour. This effect could tentatively be explained by the relatively low degree of association of about $5 \%$ as determined previously. The addition of a 120-fold excess of pyrene shows no further improvement of the catalytic activity. This result suggests that the influence of pyrene within this area of degree of association (both about 50\%) is nearly identical. Further, a time dependent catalytic behaviour can be observed. During the first 2 hours samples with anthracene and pyrene show a 10-fold increased activity. This increase is reduced at 4 hours to a factor of 5 and at 6 hours to a factor of 3 . After 
Table 4 TONs of RutpphzPd, ${ }^{a}$ RutpphzPd with anthracene and RutpphzPd with pyrene after a certain time of LED light irradiation; values in brackets illustrate the standard deviation

\begin{tabular}{lllll}
\hline Irradiation time [h] & 1 & 2 & 4 & 6 \\
\hline $\begin{array}{l}\text { TON RutpphzPd + } \\
\text { anthracene (80-fold) }\end{array}$ & $5.3(0.5)$ & $19.3(2.0)$ & $58.4(2.8)$ & $100.9(0.6)$ \\
$\begin{array}{l}\text { TON RutpphzPd + } \\
\text { pyrene (80-fold) }\end{array}$ & $2.2(0.6)$ & $15.5(0.6)$ & $57.4(9.2)$ & $93.3(5.0)$ \\
$\begin{array}{l}\text { TON RutpphzPd + } \\
\text { pyrene (120-fold) }\end{array}$ & $2.9(1.2)$ & $13.8(7.9)$ & $44.4(8.7)$ & $88.6(6.7)$ \\
$\begin{array}{l}\text { TON RutpphzPd + } \\
\text { pyrene (5-fold) }\end{array}$ & $0.7(0.1)$ & $2.7(0.1)$ & $16.8(1.1)$ & $34.8(3.6)$ \\
TON RutpphzPd & $0.3(0.2)$ & $1.2(0.1)$ & $11.7(0.8)$ & $33.7(4.5)$ \\
${ }^{a}$ Final TON for all experiments was $190 \pm 10$. & & \\
\end{tabular}

$24 \mathrm{~h}$ no further increase in $\mathrm{H}_{2}$ formation was observed for all samples and the final TON was identical within experimental errors (Tables 4 and $\mathrm{S} 1 \dagger$ ).

Both aromatic compounds, anthracene and pyrene, show an almost identical effect on the catalytic activity of RutpphzPd, which is surprising considering the previously discussed photocatalytic dimerization of anthracene. As there is no $\pi-\pi$-interaction possible between the anthracene dimer and RutpphzPd, one would expect a much less pronounced effect on the catalytic activity for anthracene compared to pyrene. To investigate this aspect in more detail, in situ UV/visspectroscopy was applied. Therefore a sample containing the photocatalyst RutpphzPd $(c=3.5 \mu \mathrm{M})$, anthracene $(2.8 \mathrm{mM})$, water $($ vol $\%=0.5)$ and TEA $(0.1 \mathrm{M})$, was irradiated under exclusion of oxygen and the changes of the anthracene absorption in the range of 300-400 $\mathrm{nm}$ were investigated.

Fig. 8 shows that in the presence of TEA only a slight decrease of the anthracene related absorption bands was observed. Hence, the formation of the hydrogen evolving photocatalytically active RutpphzPd species must occur faster and more efficiently than the energy transfer from the excited ruthenium centre to the anthracene as this would lead to the formation of the anthracene dimer.

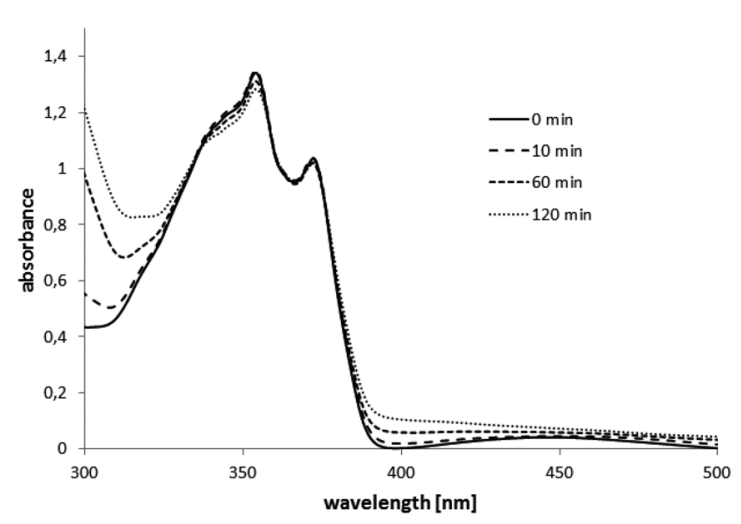

Fig. 8 Changes in the absorption spectrum of anthracene with RutpphzPd under catalytic conditions with TEA as an electron donor $(c$ (anthracene $)=0.28 \mathrm{mM}, c($ RutpphzPd $)=3.5 \mu \mathrm{M}, c($ TEA $)=0.1 \mathrm{M}$, vol\% $\left.\left(\mathrm{H}_{2} \mathrm{O}\right)=0.5 \%\right)$ with continuous LED light irradiation $(470 \mathrm{~nm})$.
In order to investigate the photochemical interaction between Rutpphz and anthracene in solution in more detail Stern-Volmer analyses were performed. The emission quenching of Rutpphz by anthracene in acetonitrile could be analysed and yielded a dynamic Stern-Volmer constant of $K_{\mathrm{SV}}=1000 \pm$ $14 \mathrm{M}^{-1}$ (see ESI Fig. S14 $\dagger$ ). An interpretation of this observation is fundamentally limited, as we have no association Stern-Volmer constant data from ${ }^{1} \mathrm{H}-\mathrm{NMR}$ spectroscopy investigation. However, the fact that $\mathrm{H}_{2}$ evolution is possible in the presence of anthracene despite this relatively high constant is another indication that the large excess of TEA in catalytic mixtures inhibits the dimerization of anthracene.

A very tempting interpretation of the observed positive effects utilises the known light switch effect for ruthenium oligopyridophenazine complexes. As recently shown by X-ray structural analysis $\pi-\pi$-interaction between the phenazine ligand and base pairs of the DNA protects the phenazine motive thus stabilising the luminescent states. ${ }^{4,48}$ We investigated therefore whether the interaction between pyrene and RutpphzPd shows positive steric effects too. In the case of the structurally related $\mathrm{Ru}(\mathrm{bpy})_{2} \mathrm{dppz}^{2+}$ the addition of DNA leads to an intercalation of the planar dppz ligand into the DNA base pairs, which protects the phenazine moiety from hydrogen bond formation with water and so "switches on" the ruthenium centre based emission, which is otherwise quenched by water. $^{49,50}$ To test whether a similar shielding effect can be observed for pyrene stacking on RutpphzPd, emission-quenching experiments were performed. Since the dinuclear RutpphzPd is non-emissive, the mononuclear Rutpphz was used as the model compound instead. Therefore the emission intensities of probes containing Rutpphz $(c=1 \mu \mathrm{M})$ and pyrene $(c=80 \mu \mathrm{M})$ were compared to those additionally containing water $(c=1.8 \mathrm{M})$. Surprisingly, the addition of pyrene had no positive effect on the emission quenching by water (see ESI Fig. S16 $\dagger$ ). Hence, a DNA like protection of the phenazine unit as observed for $\mathrm{Ru}(\mathrm{bpy})_{2} \mathrm{dppz}^{2+}$ is a rather unlikely explanation for the observed effects. Identical investigations with anthracene were not performed due to its dimerization.

\section{Conclusions}

Supramolecular $\pi$ - $\pi$-interaction is a dominant feature in the intermolecular interaction of tetrapyridophenazine ruthenium complexes as shown by solution based NMR and solid state $\mathrm{X}$-ray investigations. Within this context we here present the first detailed investigation of the solid state structure of RutpphzPd. It is possible to utilize this interaction for the formation of relatively stable one-to-one associates containing one planar polyaromatic partner, pyrene. Detailed investigations with anthracene as a related organic partner have been precluded due to the fast photocatalytic dimerization of anthracene induced by the ruthenium complex. These results open a structural aspect as the formation of defined adducts based on a specific structural property is evident. Furthermore, a significant degree of photochemical interaction between the 
aromatic binding partner and the ruthenium complex is evident. In combination construction of advanced functional supramolecular architectures structurally based on carefully adjusted $\pi-\pi$-interaction performing light driven reactions seems feasible.

The investigations on the effect of anthracene and pyrene addition on the photocatalytic activity of RutpphzPd yielded very similar results. In view of the observed photocatalytic dimerization taking place with anthracene, this similarity is a very surprising result. The addition of an 80 -fold excess of the planar aromatic carbon species leads to a reduced induction period and increased turnover frequency during the initial phase of catalysis. The hypothetical explanation for this observation could be the supramolecular protection of the tpphzligand similar to the DNA induced light switch effect ${ }^{34}$ by the polyaromatic carbon compounds. This could not be substantiated since the addition of water to a Rutpphz/pyrene mixture did lead to a significant loss of emission intensity. Another potential explanation could be the break up of RutpphzPd aggregates due to the interaction with the polyaromatic compounds resulting in a faster generation of the reactive species under photocatalytic conditions. At first sight the result for the anthracene effect on the photocatalytic behavior is puzzling but could be explained by in situ UV/vis spectroscopic investigations of the active catalytic system. Obviously the photochemical reduction of the excited ruthenium complex is significantly faster than the energy transfer between the ruthenium centre and the anthracene. This aspect may open an indirect access to rate constants within active working photocatalysts. These constants are currently difficult to obtain due to the transient nature of any electronically excited state in active catalysts.

The results shown suggest that the activity of molecular photocatalysts can be tuned by carefully exploiting supramolecular effects. This area will require more in-depth analysis in order to be fully exploited. The observed effects in connection with anthracene point towards caution with respect to transferring conclusions from model experiments into real catalytic reactions.

\section{Acknowledgements}

This research was supported by the German Research Association ((DFG SFB 583, DFG GRK 1626, MP and RS), the Deutsche Bundesstiftung Umwelt (DBU, CP), the Elitenetzwerk Bayern (RS), the Graduate School Molecular Science FAU Erlangen Nuremberg (RS) and the Carl-Zeiss-Stiftung (DS). Furthermore we thank Prof. Dr G. Taubmann for his kind support.

\section{Notes and references}

1 V. Balzani, Photochemical molecular devices, Photochem. Photobiol. Sci., 2003, 2, 459.

2 C. Li, M. Wang, J. Pan, P. Zhang, R. Zhang and L. Sun, J. Organomet. Chem., 2009, 694, 2814.
3 H. Ozawa, M. Haga and K. Sakai, J. Am. Chem. Soc., 2006, 128, 4926.

4 A. Fihri, V. Artero, A. Pereira and M. Fontecave, Dalton Trans., 2008, 5567.

5 A. Fihri, V. Artero, M. Razavet, C. Baffert, W. Leibl and M. Fontecave, Angew. Chem., Int. Ed., 2008, 47, 564.

6 M. Elvington, J. Brown, S. M. Arachchige and K. J. Brewer, J. Am. Chem. Soc., 2007, 129, 10644.

7 S. Rau, B. Schäfer, D. Gleich, E. Anders, M. Rudolph, M. Friedrich, H. Görls, W. Henry and J. G. Vos, Angew. Chem., Int. Ed., 2006, 45, 6215.

8 M. Karnahl, C. Kuhnt, F. W. Heinemann, M. Schmitt, S. Rau, J. Popp and B. Dietzek, Chem. Phys., 2012, 393, 65.

9 F. Li, Y. Jiang, B. Zhang, F. Huang, Y. Gao and L. Sun, Angew. Chem., Int. Ed., 2012, 51, 2417.

10 S. Sato, T. Morikawa, T. Kajino and O. Ishitani, Angew. Chem., Int. Ed., 2013, 52, 988.

11 Y. Tamaki, T. Morimoto, K. Koike and O. Ishitani, Proc. Natl. Acad. Sci. U. S. A., 2012, 109, 15673.

12 E. Amouyal, Sol. Energy Mater. Sol. Cells, 1995, 38, 249.

13 J.-M. Lehn and J.-P. Sauvage, Nouv. J. Chim., 1977, 1, 449.

14 K. Kalyanasundaram, J. Kiwi and M. Grätzel, Helv. Chim. Acta, 1978, 61, 2720.

15 M. Kirch, J.-M. Lehn and J.-P. Sauvage, Helv. Chim. Acta, 1979, 62, 1345.

16 S. Hansen, M. Klahn, T. Beweries and U. Rosenthal, ChemSusChem, 2012, 5, 656.

17 E. Amouyal, Sol. Energy Mater. Sol. Cells, 1995, 38, 249.

18 K. Maeda and K. Domen, J. Phys. Chem. Lett., 2010, 1, 2655.

19 J. R. Bolton, A Review Sol. Energy, 1996, 57, 37.

20 Y. H. Hu, Angew. Chem., Int. Ed., 2012, 51, 12410.

21 M. Karnahl, C. Kuhnt, F. Ma, A. Yartsev, M. Schmitt, B. Dietzek, S. Rau and J. Popp, ChemPhysChem, 2011, 12, 2101.

22 M. Karnahl, C. Kuhnt, F. W. Heinemann, M. Schmitt, S. Rau, J. Popp and B. Dietzek, Chem. Phys., 2012, 393, 65.

23 S. Losse, J. G. Vos and S. Rau, Coord. Chem. Rev., 2010, 21-22, 2492.

24 S. Tschierlei, M. Presselt, C. Kuhnt, A. Yartsev, T. Pascher, V. Sundström, M. Karnahl, M. Schwalbe, B. Schäfer, S. Rau, M. Schmitt, B. Dietzek and J. Popp, Chem. - Eur. J., 2009, 15, 7678.

25 V. Artero, M. Chavarot-Kerlidou and M. Fontecave, Angew. Chem., Int. Ed., 2011, 50, 7238.

26 H. Ozawa, M. Kobayashi, B. Balan, S. Masaoka and K. Sakai, Chem. - Asian J., 2010, 5, 1860.

27 H. Ozawa and K. Sakai, Chem. Commun., 2011, 47, 2227.

28 S. Tschierlei, M. Karnahl, M. Presselt, B. Dietzek, J. Guthmuller, L. González, M. Schmitt, S. Rau and J. Popp, Angew. Chem., Int. Ed., 2010, 49, 3981.

29 S. D. Bergman and M. Kol, Inorg. Chem., 2005, 44, 1647.

30 D. Gut, A. Rudi, J. Kopilov, I. Goldberg and M. Kol, J. Am. Chem. Soc., 2002, 124, 5449.

31 S. D. Bergman, D. Reshef, S. Groysman, I. Goldberg and M. Kol, Chem. Commun., 2002, 2374. 
32 S. D. Bergman, D. Reshef, L. Frish, Y. Cohen, I. Goldberg and M. Kol, Inorg. Chem., 2004, 43, 3792.

33 S. D. Bergman, I. Goldberg, A. Barbieri and M. Kol, Inorg. Chem., 2005, 44, 2513.

34 D. A. Lutterman, A. Chouai, Y. Liu, Y. Sun, C. D. Stewart, K. R. Dunbar and C. Turro, J. Am. Chem. Soc., 2008, 130, 1163.

35 Y. Liu, A. Chouai, N. N. Degtyareva, D. A. Lutterman, K. R. Dunbar and C. Turro, J. Am. Chem. Soc., 2005, 127, 10796.

36 S. Rau, B. Schäfer, D. Gleich, E. Anders, M. Rudolph, M. Friedrich, H. Görls, W. Henry and J. G. Vos, Angew. Chem., Int. Ed., 2006, 45, 6215.

37 G. M. Sheldrick, Acta Crystallogr., Sect. A: Fundam. Crystallogr., 2008, 64, 112.

38 A. L. Spek, J. Appl. Crystallogr., 2003, 36, 7.

39 A. L. Spek, Acta Crystallogr., Sect. D: Biol. Crystallogr., 2009, 65, 148.

40 E. F. Wilson, H. Abbas, B. J. Duncombe, C. Streb, D.-L. Long and L. Cronin, J. Am. Chem. Soc., 2008, 130, 13876.
41 K. Ha, Acta Crystallogr., Sect. E: Struct. Rep. Online, 2010, 66, $\mathrm{m} 38$.

42 V. Steullet and D. W. Dixon, J. Chem. Soc., Perkin Trans. 2, 1999, 1547.

43 N. R. de Tacconi, R. Chitakunye, F. M. MacDonnell and R. O. Lezna, J. Phys. Chem. A, 2008, 112, 497.

44 R. R. Islangulov and F. N. Castellano, Angew. Chem., Int. Ed., 2006, 45, 5957.

45 L. Fielding, Tetrahedron, 2006, 56, 6151.

46 P. Thordarson, Chem. Soc. Rev., 2011, 40, 1305.

47 H. Niyazi, J. P. Hall, K. O’Sullivan, G. Winter, T. Sorensen, J. M. Kelly and C. J. Cardin, Nat. Chem., 2012, 4, 621.

48 J. P. Hall, D. Cook, S. R. Morte, P. McIntyre, K. Buchner, H. Beer, D. J. Cardin, J. A. Brazier, G. Winter, J. M. Kelly and C. J. Cardin, J. Am. Chem. Soc., 2013, 135, 1265212659.

49 M. Schwalbe, M. Karnahl, S. Tschierlei, U. Uhlemann, M. Schmitt, B. Dietzek, J. Popp, R. Groake, J. G. Vos and S. Rau, Dalton Trans., 2010, 39, 2768.

50 Y. Sun, S. N. Collins, L. E. Joyce and C. Turro, Inorg. Chem., 2010, 49, 4257. 